\title{
Experimental constraints on the phase stability of Ti phases at subsolidus conditions in a mafic system
}

\author{
INÊS PEREIRA ${ }^{1}$, KENNETH T. KOGA $^{2}$, EMILIE BRUAND $^{3}$ \\ AND CHRISTIAN NICOLLET ${ }^{2}$ \\ ${ }^{1}$ Universite Clermont Auvergne \\ ${ }^{2}$ Université Clermont Auvergne \\ ${ }^{3}$ Laboratoire Magmas et Volcans
}

Presenting Author: ken.koga@uca.fr

Rutile, titanite and ilmenite are the most common Ti-bearing minerals found in metamorphic rocks at variable grades. Rutile and titanite, in particular, are extremely useful minerals as they can be dated using $\mathrm{U}-\mathrm{Pb}$, and $\mathrm{Zr}$ concentrations are calibrated as geothermometers for both minerals, making them valuable petrochronometers. Previous experimental studies on MORB composition [1] established that titanite is more stable at LT-LP, rutile at HP ( $>12 \mathrm{kbar}$ ), while ilmenite at HT-LP metamorphic conditions. Despite these phase stabilities, the natural occurrence of rutile at LP $(<12 \mathrm{kbar})$ and titanite at $\mathrm{HP}(>20 \mathrm{kbar})$ and ilmenite at both HP and LP indicate strong uncertainties on our current understanding about their stability. [2] demonstrated a non-trivial compositional effect on the titanite-out reaction for granitoid compositions (2-4 kbar). More experimental constraints are lacking for MORB compositions, including experiments covering the $400-600{ }^{\circ} \mathrm{C}$ range.

Here we present the first results of a set of experiments run in a piston-cylinder apparatus using an NNO outer capsule and an inner gold capsule. We used two starting materials made of a classical pulverised MORB, molten into a glass, with titanite and rutile as well as a few initial silicate mineral seeds, promoting nuclei for mineral overgrowth. All seeds were characterized by EPMA. One of the starting compositions had Ti powder added, which resulted in two distinctive $\mathrm{Ti} / \mathrm{Ca}$ values. More than 20 experiments were conducted, with pressure ranging between 12 and $23 \mathrm{kbar}$, and between 750 and $400{ }^{\circ} \mathrm{C}$ in water-saturated conditions and using a cold pressure-seal capsule technique. Due to the challenging LT experiments, equilibrium is not attained, but dissolution and precipitation features are often observable. Epidote is one of the first minerals to nucleate and grow, followed by amphibole. We show that when $\mathrm{Ti} / \mathrm{Ca}$ is high, rutile is stable even at lower pressures, and when $\mathrm{Ti} / \mathrm{Ca}$ is low, titanite seeds appear metastable even at higher pressures (19 kbar) at low temperatures. This is in agreement with petrological observations.

[1] Liou, et al. (1998). Schweiz. Mineral. Petrog. Mitt., 78, 317-335.

[2] Angiboust, S., \& Harlov, D. (2017). Am. Min., 102, 16961708 . 